\title{
Interaction matters? : exploring interactive music as a reminder to break sedentary office time
}

\section{Citation for published version (APA):}

Ren, X., Lu, Y., Visser, V. J. J., Le, P. D. H., \& van den Burg, R. (2017). Interaction matters? : exploring interactive music as a reminder to break sedentary office time. In 34th International Symposium on Automation and Robotics in Construction, 28 June - 1 July 2017, Tapei, Taiwan (pp. 1099-1106) https://doi.org/10.22260/ISARC2017/0151

DOI:

10.22260/ISARC2017/0151

Document status and date:

Published: 01/01/2017

\section{Document Version:}

Publisher's PDF, also known as Version of Record (includes final page, issue and volume numbers)

\section{Please check the document version of this publication:}

- A submitted manuscript is the version of the article upon submission and before peer-review. There can be important differences between the submitted version and the official published version of record. People interested in the research are advised to contact the author for the final version of the publication, or visit the $\mathrm{DOI}$ to the publisher's website.

- The final author version and the galley proof are versions of the publication after peer review.

- The final published version features the final layout of the paper including the volume, issue and page numbers.

Link to publication

\section{General rights}

Copyright and moral rights for the publications made accessible in the public portal are retained by the authors and/or other copyright owners and it is a condition of accessing publications that users recognise and abide by the legal requirements associated with these rights.

- Users may download and print one copy of any publication from the public portal for the purpose of private study or research.

- You may not further distribute the material or use it for any profit-making activity or commercial gain

- You may freely distribute the URL identifying the publication in the public portal.

If the publication is distributed under the terms of Article 25fa of the Dutch Copyright Act, indicated by the "Taverne" license above, please follow below link for the End User Agreement:

www.tue.nl/taverne

Take down policy

If you believe that this document breaches copyright please contact us at:

openaccess@tue.nl

providing details and we will investigate your claim. 


\title{
Interaction Matters? Exploring Interactive Music as a Reminder to Break Sedentary Office Time
}

\author{
Xipei Ren, Yuan Lu, Vincent Visser, P.D.Huy Le and Reijn van den Burg \\ Department of Industrial Design, Eindhoven University of Technology, the Netherlands \\ E-mail: \{x.ren, y.lu\}@tue.nl, \{v.j.j.visser, p.d.h.le, r.s.v.d.burg\}@student.tue.nl
}

\begin{abstract}
-
This paper presents a within-subject field test $(n=24)$ with Flow platform, a smart cushion that uses interactive music to motivate office workers to break excessive sedentary time. In this study, we compared continuous music and interactive music as reminders to inform sedentary time by every 15-min. After each treatment, a questionnaire adapted from Flow State Scale was used to measure participants' experiences and thus motivations with interactive and non-interactive music. Moreover, a postinterview was conducted with every participant individually to gather insights on the challenges and opportunities for current design. This study examines if the interactivity as an additional factor could influence the music as a motivator to prevent sedentary behaviours among office workers. Our findings suggest a further design iteration to appropriate the concept more to the context of office.
\end{abstract}

\section{Keywords -}

Sedentary behaviour; Interactive music; Flow experience; Motivational design

\section{Introduction}

Nowadays, the rapid growth of office automation is largely associated with sedentary behaviours, which has been proven to threaten cardio metabolic health among office workers and thus to contribute to various preventable causes of death in later life stage [1]. Evidence shows that the effect of too much sitting displaces the benefit from partial exercise [2]. To overcome this issue, Owen et al. [3] suggested to break excessive sedentary time and to encourage light intensity exercises ${ }^{1}$ in repeated sessions throughout the day, such as the frequent changes of sitting postures from one to another. Based on this observation, we previously designed Flow platform [4], a novel technology that learns and logs sitting behaviour from

\footnotetext{
1 light intensity exercise: the exercise in the energy expenditure range of 1.9 to 2.9 METs (multiples of the basal metabolic rate)
}

users and in return uses interactive music to encourage users to change sitting postures with different dynamics.

From the earlier study [4], we learned that music in general motivates physically more active performance. Yet, it is unclear: (i) if the current interactivity of music in Flow platform can leverage the motivation to aid sedentary behaviours among office workers; (ii) how to improve the current interaction for a better motivation in the future.

To investigate this further, we conducted a withinsubject field-test $(n=24)$ with Flow platform, where we compared continuous music and interactive music respectively as reminders to inform sedentary time by 15-min intervals. We carried each treatment out by an hour per participant and recorded their sitting posture data by our technology. After each treatment, participants were asked to fill in the questionnaire adapted from Flow State Scale [5], a 36-item five Likert Scale questionnaire explains why people engage in certain activities intrinsically, to understand their experiences using Flow platform and thus motivations to sit actively with non-interactive/interactive music. Moreover, we also conducted a post hoc interview with every participant individually to gain some insights for further design.

By comparing quantitative data, we learned the current interaction could not make too much impact to prevent sedentary behaviours for target users. From the qualitative results, however, we found a few insights suggested us to implement the interactive music more appropriately for the office workers. This paper makes two contributions. First, it examines interactivity as another factor to influence motivational music in aiding sedentary office people. Second, it identifies extra insights to account for when designing interactive music as an interface to support behaviour change.

This paper proceeds as follows. Next section we provide a brief overview of Flow platform [4] and the review on current ambient technologies that reduce sedentary office time, which motivate us to conduct this study. In section 3, we describe on how we designed our experiment, which is followed by the results from this study in section 4. Conclusion is given in the end. 


\section{Related Work}

\subsection{Flow Cushion}

Earlier to this study, we designed Flow platform [4], a smart cushion that can be placed on every normal chair to track and archive sitting behaviours from the user. Consequently, if the user remains one sitting posture for an extended period of time $(15 \mathrm{~min}$ in our case), the system would use the interactive music to stimulate the user to shift to the different postures according to the musical dynamics (see Figure 1).

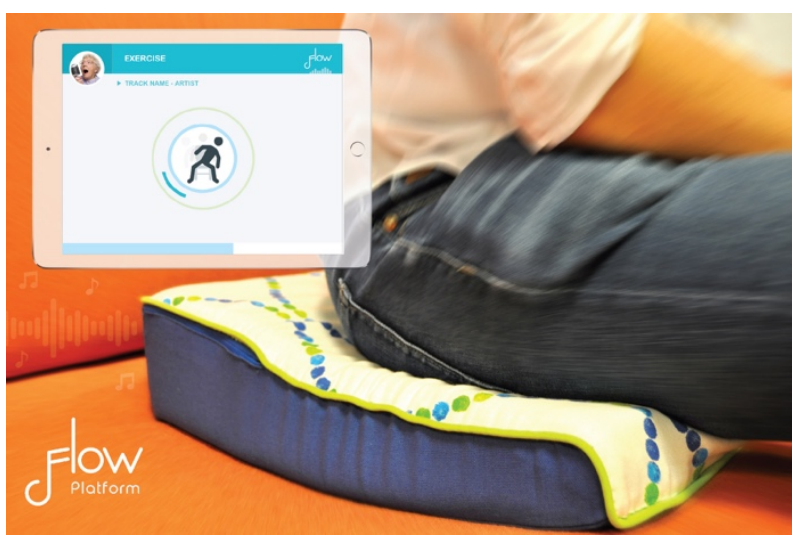

Figure 1. Flow platform is designed to reduce sedentary time by enabling the user to interact with different musical dynamics.

Flow platform was developed in three steps, consisting sensor implementation, interaction design, and experience design. Since in this study we have only examined on the interactive music part, in the following we elaborate on the first two steps specifically to appropriate how we implement the system technically and how the music works in the system.

\subsubsection{Sensor Implementation}

Inspired by previous design research [6] and products [7], we built a fabric pad (see Figure 2) that could be embedded into the seat cushion. Six square type force resistor sensors (FRS) were placed according to sedentary pressure map for efficient detection area coverage. We connected the sensor pad with Arduino Yun, a small micro-controller prototyping board, which connected to a Bluetooth module. In this way, Flow platform was able to synchronise data periodically (once every second) over Bluetooth to computer or smartphone.

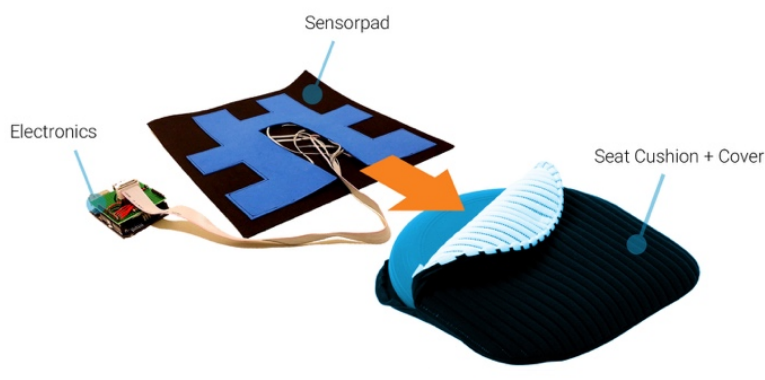

Figure 2. The sensor-pad of Flow platform, which contains six square FRS configured with the reference of [8].

To determine the user's sitting posture, we applied a specialized Artificial Neuron Network (ANN) [4] in the software (see Figure 3), by which the system can calibrate movement range according to different person. With the Wi-Fi connection, therefore, Flow platform can measure and analyse the user's sitting behaviour over a distance and accordingly customise the sitting exercise.

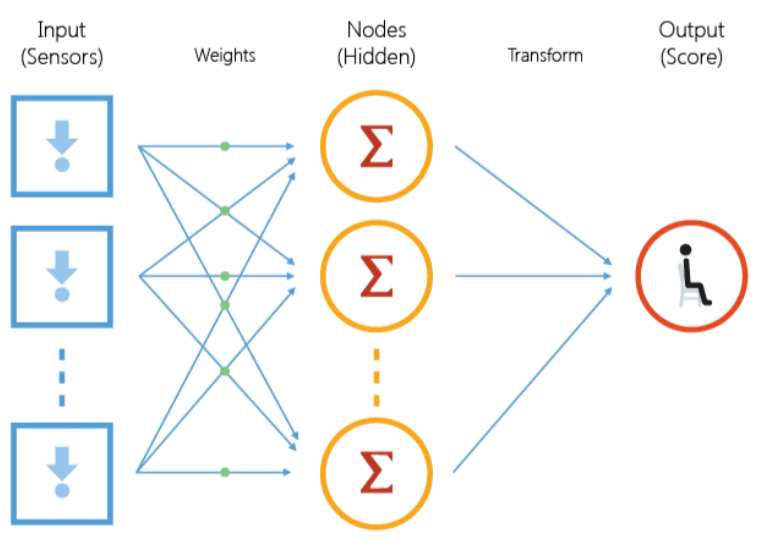

Figure 3. The ANN used in Flow platform.

\subsubsection{Interaction Design}

The musical interaction in Flow platform was designed based on observation [4] in an elderly care centre as well as several ideation sessions in the university. The instrumental music was chosen in the end aiming to improve the exercise adherence [9]. We designed the mechanism as follows (see Figure 4): If the user sits stationary for 15 minutes, the volume of the music will decrease gradually. Then the user needs to shift the sitting postures actively to literally interact with the music for 2 minutes. When the goal has been achieved, the volume goes back to the normal range. 


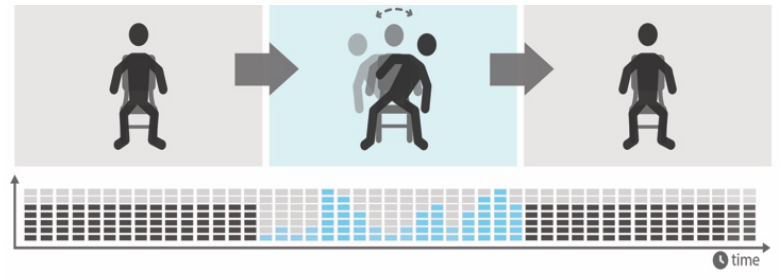

Figure 4. the logic of how the interactive music work in Flow platform to support the user to avoid sedentariness.

This system was originally designed for the elderly people. During the user test and expert consultation, however, both the target users and physiotherapists suggested the musical intervention we used here could also be used for the office workers to aid the prolonged sedentary working time. They gave this advice as they thought the interactive music reminds people to be aware of the sedentary behaviour in a non-obtrusive way. In addition, as far as we know, music can sometimes accompany office workers during work hours to increase the work efficiency [10]. Therefore, we decide to examine our design with the office workers as well to explore the opportunities and challenges of our design.

In fact, designing ambient technology [11] to remind users on the sedentary behaviour in the office settings was not new in HCI, as in such context people wish to focus on the task at hand rather than bothered by the technology [12]. Many prior studies have been investigated this area using different interaction techniques [13]. In the following, we review the earlier works in detail.

\subsection{Ambient Display to Aid Sedentary Time}

As a growing design and research focus in HCI, ambient technology [11] is featured by presenting information to users requiring the smallest amount of attention and allows users to interact with the technology in a non-obtrusive way. In the scope of this study, ambient technology offers a trade-off between raising office workers' awareness on sedentary behaviours and the demand to focus on work at hand. As one of the earliest study in this area, Jafarinaimi et al. [14] identified design guidelines for ambient display to promote physically active behaviours, consisting abstract, non-intrusive, public, and aesthetic. They also developed a tangible prototype called Breakaway using biomimetic metaphor to further explain their design goals. Similar to Breakaway, Hong et al. [15] designed a flower-shaped avatar to provide an ambient feedback about different sitting behaviours. In addition, other display techniques, such as ambient lighting [16] [17] and haptic feedback [18], have also been widely employed in relevant design.
In a more recent $\mathrm{PhD}$ project, Probst [19] explored this area from a task-based perspective, where different forms of peripheral interaction [20] were embedded in different objects (e.g. [21], [22]) in the office environment. As such, the proposed technologies enable office workers to use diverse body movements to execute different office tasks in order to enhance physical activeness during work hours. Probst's works clearly broaden ambient technology for sedentary behaviour from only stimulating the periphery of perception to stimulating the periphery of physical interaction [20]. In line with this direction, Flow platform uses interactive music to not only remind people in a way fits for their working routine, but also provide a channel for them to do physical exercise while working without any disturbance.

To examine further, we set out a within-subject experiment $(n=24)$ to explore the potential role of interactive music in Flow platform to motivate more activeness among office workers during work hours.

\section{Experiment Design}

\subsection{Scenario}

To better explain how Flow Cushion should work in the workplace environment, we apply it to a use case and propose the following scenario:

Jeff is a junior computer programmer, who has four tasks to accomplish this week. Therefore, he spent eight hours per day sitting at the desk to write codes for two ongoing projects, look up the algorithms for a new project, and write a report for a past project. He starts to feel pain in his back and neck recently and wants to reduce the prolonged sitting. Yet, he always forgets how long he has been sitting when focusing on the task at hand. Plus, he does not want to use any system that literally takes him away from the work. He looks up the products that match his needs and then finds Flow platform. He really appreciates the idea of using music to remind the inappropriate sitting behaviours, as he always listens to the music while working. So he thinks the musical reminder will fit his working routine in a non-obtrusive way. After installed Flow cushion on his chair and Flow app on his computer, he wears headset, switches on his favourite music album, and carries on working. 15 minutes later, he finds the music becomes lower. Then he changes his posture one to another randomly within his preferred movement range and keeps his main focus on current task. After several attempts on different movements, the volume of the music backs to the normal range. Jeff then stops shifting postures and continue on working without any pause. At the end of the week, Jeff finishes all the four tasks in time and still feels energetic for the weekend. Jeff thinks 
that Flow platform can help him to maintain physical active during the work without any interruption. He feels refreshed after the sitting exercise, rewarded when the music comes back, and more focused on the work.

This scenario illustrates how the interactive music system works in the workplace settings, following the design guideline from [14], which abstracts the information and makes the presentation non-obtrusively. Our system also provides office workers a channel to interact with the music in a pleasant way. To eliminate the disturbance on co-workers in the same place, Flow platform in this case is advised to use headset to restrict the publicity of the music.

\subsection{Participants}

We recruited the participants by spreading information via word-of-mouth through a snowball sampling approach: We began by asking people we knew that exhibited similar characteristics as our target users. We then asked them to pass along the information about our study to their social contacts. Eventually, there were 24 volunteers participating in the study. This closes to the minimum number of people required as to obtain statistically sound results. The participants were all university students or junior office workers. They were aged between 18 and 25 (mean age: 21.46, standard deviation: 1.67).

\subsection{Procedure}

Each participant was subjected to two tests - one test in which they used the FLOW cushion with interactive music, and one test in which they used the FLOW cushion with non-interactive music. $50 \%$ of the participants was subjected to the interactive music first, the other $50 \%$ to the non-interactive music.

Before each test, participants were asked to sign a consent form and were briefly introduced to the concept of the FLOW platform - that the cushion registers their sitting behaviour and that the music was part of the platform. Moreover, participants were instructed that they were allowed to do any activity as long as they remained seated on the cushion. Participants were furthermore not instructed to achieve any particular goal.

The sitting positions of the participants were logged during the tests. Each of these tests had a duration of one hour. We pre-set the volume interruption of the music at 15-min interval persisting 2-min slot for interaction. At the end of each test, participants were immediately instructed to fill in a questionnaire and to answer various open questions regarding their experience with the FLOW cushion and the music.

\subsection{Data Collection}

During each test, three forms of data were collected: the registrations of shifts in postures, questionnaire results (quantitative data) and interview results (qualitative data).

\subsubsection{Registration of the Shift in Postures}

The software automatically registers and collects the date and time of each shift in posture and the specific sitting position (represented as a number) during each test. This data is collected during both the tests with continuous music and interactive music, and will be compared with each other in order to conclude whether there are any significant differences.

\subsubsection{Questionnaire}

The questionnaire is based on the FLOW state scale. It measures nine aspects experienced by the participant during the tests: challenge-skill balance, clear goals, paradox of control, autotelic experience, transformation of time, loss of self-consciousness, concentration on task at hand, unambiguous feedback, and actionawareness merging. These categorized questions give us a better understanding of the challenges and feelings experienced by the participants during the tests [5].

Challenge-Skill Balance (continuous music (C): $\alpha=.590$; interactive music (I): $\alpha=.362$ ): "In flow, the person perceives a balance between the challenges of a situation and one's skills, with both operating at a personally high level."

Action-Awareness Merging (C: $\alpha=.565$; I: $\alpha=.728$ ); "Involvement in the flow activity is so deep that it becomes spontaneous or automatic. There is no awareness of self as separate from the actions one is performing."

Clear Goals (C: $\alpha=.912$; I: $\alpha=.858$ ): "Goals in the activity are clearly defined (either set in advance or developed out of involvement in the activity), giving the person in flow a strong sense of what he or she is going to do."

Unambiguous Feedback (C: $\alpha=.823$; I: $\alpha=.795$ ): "Immediate and clear feedback is received, usually from the activity itself, allowing the person to know he or she is succeeding in the set goal."

Concentration on Task at Hand (C: $\alpha=.876$; I: $\alpha=.844)$ : "Total concentration on the task at hand occurs when in flow."

Paradox of Control (C: $\alpha=.725 ; \mathrm{I}: \alpha=.798)$ : “ $A$ sense of exercising control is experienced, without the person actively trying to exert control."

Loss of Self-Consciousness (C: $\alpha=.395$; I: $\alpha=.832$ ): "Concern for the self disappears during flow as the person becomes one with the activity."

Transformation of Time (C: $\alpha=.797 ; \mathrm{I}: \alpha=.839$ ): "Time alters perceptibly, either slowing down or 
speeding up. Alternatively, time may simply become irrelevant and out of one's awareness."

Autotelic Experience (C: $\alpha=.900 ; \mathrm{I}: \alpha=.824)$ : “ $A n$ autotelic experience is an intrinsically rewarding experience."

\subsubsection{Interview}

At the end of each session with the FLOW cushion, participants were asked a few open questions regarding their experience with the flow cushion and the interactive/non-interactive music. All the interviews were audio recorded upon the approval of the participants. Although not all interviews were completely similar, they generally followed the script below:

\section{After non-interactive music treatment:}

- What do you feel with FLOW?

- How did you feel about doing exercises, such as shifting postures, with the FLOW cushion?

- What do you think about music as a reminder to break your sedentary time?

- What kind of music would you like to hear with FLOW?

\section{After interactive music treatment:}

- What do you feel with FLOW?

- How did you feel about doing exercises, such as shifting postures, with the FLOW cushion?

- What do you think of interactive music as a reminder for shifting postures?

- What kind of music would you like to hear with FLOW?

- Would you like to use the FLOW cushion more often?

- What would you like to change to the design?

\subsection{Data Analysis}

\subsubsection{Registered Posture Data Analysis}

We initially planned to compare the registered posture data between the treatment with continuous music and another with interactive music, to check if interactive music contributes to more posture shifts at a significant level. However, due to a logical error in our program in the beginning, we did not successfully archive the posture data in our cloud. We only realised this error at the very last stage of the experiment. Given this issue, we did not collect the complete sitting data from each test for any participant. In this study, therefore, we are not able to analyse if there was an impact of interactive music for more dynamic sitting posture shifts for the office workers. Yet, it was a meaningful lesson for us to learn that before the experiment every single detail needs to be double- checked in case any error occurs in the experiment. Moreover, this mistake also helped us to fine-tune our program technically for future design and research.

\subsubsection{Questionnaire Data Analysis}

To compare the questionnaire data between two treatments, the normality test of distribution was conducted at first using Kolmogorov-Smirnov test. Given most of the categories between two treatments were not normally distributed, we then conducted related-sample nonparametric analysis using Wilcoxon test to compare the difference between two tests.

\subsubsection{Interview Data Analysis}

We clustered qualitative data based on logical closeness on different feedbacks following the inductive approach [23]. Here we aimed to inquire any valuable insights that emerged from our study to confirm our current design concept to some extent as well as to enlighten our future design.

\section{Findings}

In this section, we report on the result from both our questionnaire and our post hoc interviews.

\subsection{Quantitative Findings}

Table 1. Mean score and comparison of flow experience between continuous and interactive music

\begin{tabular}{|c|c|c|}
\hline $\begin{array}{l}\text { Continuous } \\
\text { Music }(n=24)\end{array}$ & $\begin{array}{c}\text { Interactive } \\
\text { Music }(n=24)\end{array}$ & Wilcoxon Test \\
\hline \multicolumn{3}{|c|}{ Challenge-Skill Balance } \\
\hline M 3.24 SD 0.70 & M 3.29 SD 0.62 & $Z-.607 P .544$ \\
\hline \multicolumn{3}{|c|}{ Action-Awareness Merging } \\
\hline M 3.67 SD 0.63 & M 3.69 SD 0.77 & $Z-.677 P .498$ \\
\hline \multicolumn{3}{|l|}{ Clear Goals } \\
\hline M 3.77 SD 1.05 & M 3.46 SD 1.09 & $Z-1.569 P .117$ \\
\hline \multicolumn{3}{|c|}{ Unambiguous Feedback } \\
\hline M 3.20 SD 0.73 & M 3.18 SD 0.90 & $Z-.264 P .792$ \\
\hline \multicolumn{3}{|c|}{ Concentration on Task at Hand } \\
\hline M 3.17 SD 1.03 & M 2.84 SD 0.99 & $Z-1.412 P .158$ \\
\hline \multicolumn{3}{|l|}{ Paradox of Control } \\
\hline M 3.82 SD 0.62 & M 3.64 SD 0.92 & $Z-1.523 P .128$ \\
\hline \multicolumn{3}{|c|}{ Loss of Self-Consciousness } \\
\hline M 4.14 SD 0.63 & M 4.17 SD 0.86 & $Z-.328 P .743$ \\
\hline \multicolumn{3}{|c|}{ Transformation of Time } \\
\hline M 2.54 SD 1.00 & M 2.53 SD 1.10 & $Z-.019 P .985$ \\
\hline \multicolumn{3}{|c|}{ Autotelic Experience } \\
\hline M 2.85 SD 0.78 & M 2.99 SD 0.82 & $Z-1.073 P .283$ \\
\hline
\end{tabular}

As can be seen from Table 1, the Wilcoxon test 
suggests none of the considered categories between two treatments are different at the significant level below 0.05 . From this study, we learned that the current interactivity of the music in Flow platform made no different flow state to the normal music. For the office workers, we therefore conclude that using both forms of music to break sedentary time causes the engaging user experiences at the same level.

\subsection{Qualitative Findings}

Our findings from the interviews compensate the quantitative results from the questionnaire. In what follows, we present the general experience with Flow platform as well as the opportunities for future design.

\subsubsection{General Experience}

From the interview, the majority of participants indicated that Flow platform increased their awareness about their sedentariness and posture behaviour. More specifically, both two musical treatments were considered to be appropriate motivators for the participants to get sitting posture shifts. We also learned that the future use of Flow platform was generally considered plausible by most of our participants. However, participants, who already moved often during work, did not see the clear benefit from Flow to make them more active on the working routine. Which means that our design is supposed to be more appropriate for the real sedentary office workers. This finding suggests a thorough study on profiling the target users should be done here to better positioning our work for the context.

What is more, a few participants added the comments that the final execution of the concept would influence their willing to use the system to some extent. Therefore, we need to do more works to finalise the detail design of Flow platform. In the part of design opportunities, we will discuss this further.

\subsubsection{Design Opportunities}

During the interviews, we also found some issues that made negative impacts on our test. However, we believe these findings will help us to refine the current design largely and in turn appropriate Flow platform more to our target users. Below we discuss on what participants found about our design. In response, we propose the design strategies we are going to use to optimise Flow platform.

First of all, although the Flow cushion itself is a prototype, some participants left the remarks that the current design was not being very physically comfort enough to support long-term use. These comments were basically related to the wires were exposed on the seat. Since our prototype needs an external power supply for long-term usage, we connected the cushion with a power plug during our experiments. This setting, however, restricted participants' freedom to move during the study. For the future step, we consider to embed a rechargeable battery in the cushion, which has enough capacity for longer time use (e.g., one week per charge). As such, we are confident that the problem in regard with the ergonomics of Flow platform will be addressed.

Second, most of the concerns we received from the participants were pointed to the interactivity of the music we implemented in the test. On the one hand, some participants claimed that the volume of the interactive music changed too quickly for activities that require more serious concentration, and thus study and office work became irritating in the end. This suggests us to lower the speed of volume alternation. On the other hand, one participant stated that the intended effect (the interactivity of the volume) should be stronger to increase the awareness on sitting postures. All these comments suggest we should cater the changing pace for every individual. A more viable way would be enabling user to customise the speed themselves.

Third, although participants found the alternation of volume was interesting and motivational for them to break prolonged sitting, they also encouraged us to investigate on the applicability of other psycho-acoustic parameters to leverage active behaviours. For example, it is also possible to suggest an active break by slowing down the rhythm of the music. It is hard to say which parameter of music is the best motivator in our case. Following the prior suggestion, our design could be made to be more customisable to let users to select their own favourite parameter(s) and even more to pre-set diverse combinations of parameter(s) according to the context differences.

Fourth, some participants commented that different working tasks require different levels of concentrations. Thus not all types of music were appropriate in this context. Instrumental music is perhaps beneficial for physical activities, but it is too energetic for moderate exercise when the major focus was on the working task. Most of the participants suggested us to use ambient sound and peripheral music for future design.

\section{Conclusion}

In this paper, we present a within-subject user test $(n=24)$ on our design of Flow platform with office people to explore how to implement interactive music into our technology to break sedentary office time more appropriately. Our findings suggested in general the music was considered to be an appropriate motivator for the office workers to aid their sedentary behaviours. Yet there is room for our interaction design to be more 
appreciated by the target users. On the one hand, specifying sportive people and sedentary people in our case and accordingly using different design strategies would be helpful to narrow down the scope and improve the effectiveness of our design. On the other hand, the threshold of interactivity and the interactive parameters of music could be designed customisable for the end users. Moreover, the type of the music and the ergonomics of the cushion should be more comfortable for the given context. Although a lot of effort needs to be spent for further development and validation of our design, we still believe the results from this study can contribute to relevant works on the interactive music for motivational design and thus design for health and wellbeing in the HCI community.

\section{Acknowledgement}

The first author of this paper is being sponsored by China Scholarship Council (CSC). We thank all the participants who volunteered to take part in this study.

\section{References}

[1] Owen N, Bauman A, Brown W. Too much sitting: a novel and important predictor of chronic disease risk?. British Journal of Sports Medicine, 43(2): 81-83, 2008.

[2] Healy GN, Dunstan DW, Salmon J, Cerin E, Shaw JE, Zimmet PZ, Owen N. Breaks in sedentary time. Diabetes care,31(4):661-666, 2008.

[3] Owen N, Healy GN, Matthews CE, Dunstan DW. Too much sitting: the population-health science of sedentary behavior. Exercise and sport sciences reviews, 38(3):105-113, 2010.

[4] Ren X, Visser V, Lu Y, Brankaert R, Offermans S, Nagtzaam H. FLOW pillow: exploring sitting experience towards active ageing. In Proceedings of the 18th ACM International Conference on Human-Computer Interaction with Mobile Devices and Services Adjunct, page 706-713, Florence, Italy, 2016.

[5] Jackson SA, Marsh HW. Development and validation of a scale to measure optimal experience: The Flow State Scale. Journal of sport and exercise psychology, 18(1):17-35, 1996.

[6] Min DA, Kim Y, Jang SA, Kim KY, Jung SE, Lee JH. Pretty Pelvis: A Virtual Pet Application That Breaks Sedentary Time by Promoting Gestural Interaction. In Proceedings of the 33rd Annual ACM Conference Extended Abstracts on Human Factors in Computing Systems, page 1259-1264, Soul, Korea, 2015.

[7] Darma co. Darma Sit Smart. On-line: http://darma.co/index.html, Accessed: 28/03/2017.
[8] Brienza D, Kelsey S, Karg P, Allegretti A, Olson M, Schmeler M, Zanca J, Geyer MJ, Kusturiss M, Holm M. A randomized clinical trial on preventing pressure ulcers with wheelchair seat cushions. Journal of the American Geriatrics Society, 58(12):2308-2314, 2010.

[9] Schutzer KA, Graves BS. Barriers and motivations to exercise in older adults. Preventive medicine, 39(5):1056-1061, 2004.

[10] Lesiuk T. The effect of music listening on work performance. Psychology of music, 33(2):173-191, 2005.

[11] Weiser M, Brown JS. The coming age of calm technology. In Beyond calculation, page 75-85, New York, USA, 1997.

[12] Cook DJ, Augusto JC, Jakkula VR. Ambient intelligence: Technologies, applications, and opportunities. Pervasive and Mobile Computing, 5(4):277-298, 2009.

[13] Haller M, Richter C, Brandl P, Gross S, Schossleitner G, Schrempf A, Nii H, Sugimoto M, Inami M. Finding the right way for interrupting people improving their sitting posture. In IFIP Conference on Human-Computer Interaction 2011, page 1-17, Lisbon, Portugal, 2011.

[14] Jafarinaimi N, Forlizzi J, Hurst A, Zimmerman J. Breakaway: an ambient display designed to change human behavior. In Proceedings of the $23 \mathrm{rd}$ Annual ACM Conference Extended Abstracts on Human Factors in Computing Systems, page 19451948, Portland, USA, 2005.

[15] Hong JK, Koo BC, Ban SR, Cho JD, Bianchi A. BeuPo: a digital plant that you can raise and customize with your current posture. In Adjunct Proceedings of the 2015 ACM International Joint Conference on Pervasive and Ubiquitous Computing, page 1015-1020, Osaka, Japan, 2015.

[16] Fortmann J, Stratmann TC, Boll S, Poppinga B, Heuten W. Make me move at work! An ambient light display to increase physical activity. In Proceedings of the 7th International Conference on Pervasive Computing Technologies for Healthcare, page 274-277, Venice, Italy, 2013.

[17] Mateevitsi V, Reda K, Leigh J, Johnson A. The health bar: a persuasive ambient display to improve the office worker's well being. In Proceedings of the 5th Augmented Human International Conference, page 21-22, Kobe, Japan, 2014.

[18] Zheng Y, Morrell JB. A vibrotactile feedback approach to posture guidance. In IEEE Haptics Symposium, page 351-358, Waltham, USA, 2010.

[19] Probst K. Active office: designing for physical activity in digital workplaces. In Proceedings of the 14th International Conference on Mobile and 
Ubiquitous Multimedia, page 433-438, Linz, Austria, 2015.

[20] Bakker S, van den Hoven E, Eggen B. Peripheral interaction: characteristics and considerations. Personal and Ubiquitous Computing, 19(1):239254, 2015.

[21] Probst K, Lindlbauer D, Haller M, Schwartz B, Schrempf A. A chair as ubiquitous input device: Exploring semaphoric chair gestures for focused and peripheral interaction. In Proceedings of the 32nd Annual ACM Conference on Human Factors in Computing Systems, page 4097-4106, Toronto, Canada, 2014.

[22] Probst K, Lindlbauer D, Perteneder F, Haller M, Schwartz B, Schrempf A. Exploring the use of distributed multiple monitors within an activitypromoting sit-and-stand office workspace. In IFIP Conference on Human-Computer Interaction 2013, page 476-493, Cape Town, South Africa, 2013.

[23] Thomas DR. A general inductive approach for analyzing qualitative evaluation data. American journal of evaluation, 27(2):237-246, 2006. 